\title{
Socio-demographic Characteristic of Sudanese Patients on Hemodialysis at Gezira Hospital for Renal Diseases and Surgery, Gezira State, Sudan; 2018
}

\author{
Taha Ahmed Elmukashfi Elsheikh ${ }^{1, *}$, Mohamed Abdel Salam Nurein ${ }^{2}$, Mustafa Omran Mansour ${ }^{3}$ \\ ${ }^{1}$ Department of Community Medicine, University of Khartoum, Khartoum, Sudan \\ ${ }^{2}$ Department of Anatomy, University of Karrari, Khartoum, Sudan \\ ${ }^{3}$ Department of Urology, University of Gezira, Wadmadani, Sudan
}

Email address:

tahamukashfi@hotmail.com (T. A. E. Elsheikh), tahamukashfi@uofk.edu (T. A. E. Elsheikh)

${ }^{*}$ Corresponding author

\section{To cite this article:}

Taha Ahmed Elmukashfi Elsheikh, Mohamed Abdel Salam Nurein, Mustafa Omran Mansour. Socio-demographic Characteristic of Sudanese Patients on Hemodialysis at Gezira Hospital for Renal Diseases and Surgery, Gezira State, Sudan; 2018. Central African Journal of Public Health. Vol. 5, No. 6, 2019, pp. 256-260. doi: 10.11648/j.cajph.20190506.15

Received: September 11, 2019; Accepted: October 4, 2019; Published: October 15, 2019

\begin{abstract}
End stage renal disease is an irreversible renal damage leading to impairment of renal function and failure of filtration of metabolic wastes from the blood. To determine the socio-demographic characteristics of Sudanese Patients on Hemodialysis at Gezira Hospital for Renal Diseases and Surgery, Gezira State, Sudan; 2018. It was an observational study. Independent variables were socio-demographic characteristics. Dependent variable was hemodialysis. A questionnaire was used to obtain the required data. SPSS version 21 was used for data entry and analysis. Chi square test was used and $P$-value $\leq$ 0.05 was considered statistically significant. Sixty two percent of respondents were male. Minimum age was 19 years while maximum age was 70 years. Maximum affected age group was age group (36-45) years; followed by age groups (46-55) and (56-65) years. Minimum age at which disease was diagnosed was 13 years while maximum was 67 years. Regarding residency was as follow: Two percent from East State, 2\% from West State, and 96\% from Central State. For education: Twenty percent were illiterate, 6.0\% Quranic School (Khalwa), 36\% primary school, 14\% secondary school, 14\% university graduate, and $10 \%$ had postgraduate certificate. Their occupation was as follows: Twenty percent were labors, $8 \%$ were farmers, $6 \%$ were employee, $2 \%$ were merchants, $4 \%$ were students, $24 \%$ were households, $2 \%$ was from the medical field, $4 \%$ were nonemployee and $30 \%$ did not identify their occupations. Sixty six percent were married. Male is more prone to heamodialysis than female. Risk for heamodialysis increases with increased age. The married rate is an important factor related to the outcome of ESRD. Low levels of education together with low income level of employment are important factors related to ESRD.
\end{abstract}

Keywords: Socio-Demographic Characteristic, ESRD, Sudanese Patients, Gezira State

\section{Introduction}

ESRD is one of the awfully increasing conditions leading to high economic and social burden. In Sudan it affects younger people, mainly below the age of 50 years; while in developed countries the age of patients is above 60 years. The disease affects the productive age group [1]. The outcome of slowly progressive kidney damage is End-stage renal disease (ESRD). So, early detection and intervention may improve the situation and prevent the development of ESRD. The incidence rate of ESRD in the Middle East countries is 93/million population/year; while in Sudan is about 70-140/million population/year [2]. The frequency of bilateral renal agenesis is $1 / 10,000$ births, and it leads to renal failure [3].

Risk factors for chronic kidney disease: diabetes, high blood pressure, heart and blood vessel (cardiovascular) disease, smoking, obesity, glomerulonephritis, interstitial nephritis, prolonged obstruction of the urinary tract, 
vesicoureteral reflux, and recurrent kidney infection, (pyelonephritis), being African-American, Native American or Asian-American, family history of kidney disease, abnormal kidney structure, and older age [4].

Risk factors for hemodialysis: age (risk increase with age), sex (male is more than female), ethnic (African-American have higher rates), diabetes (one third of patients have diabetes), hypertension (second cause of hemodialysis), education ( $\uparrow$ with lower education), overweight, proteinuria, low hemoglobin, nocturia, hyperuricemia, genetics, smoking, high cholesterol, recreational drugs, glomerulonephritis, drug use and kidney stones, polycystic kidney disease, systemic lupus erythematosus, congenital nephrotic syndrome, and atherosclerosis [5].

ESRD has a relation to poor quality of life [6]. There is a significant statistical association between gender (female), and marital status among Iraqi Patients on heamodialysis with depression [7].

Gender (female), age (older), level of education (less educated), and marital status (divorced/widowed) are negatively affecting quality of life of patients on heamodialysis in Greece [8]. Female, increased age, unemployment, low level of education, and un-marital status are negatively associated with the outcome of ESRD [9].

In Sudan it is reported that the vulnerable group characterized by being younger, single, and less educated [10].

The majority of patients $(64.5 \%)$ on heamodialysis in Ghana are male [11]. In a study done in Cameron, among patients on heamodialysis, $66 \%$ of respondents are male; with overall mean age of 47.4 years; where mean age for men is 48.9, and for female is 44.5. So, gender and age are important factors related to ESRD [12]. It is reported in a study related to data from Asia-Africa that male is predominant $(66.7 \%)$ among patients with chronic kidney disease. In this study the mean age is $49.27 \pm 16.7$ years, married rare is $70.6 \%$, undergraduate level of education is $40 \%$, employed rate is $34 \%$, low income group represents $41.6 \%$ and middle income group represents $37.3 \%$ [13].

Aim and justification of the study: There is a gap of knowledge regarding Socio-demographic Characteristic of Sudanese Patients on Hemodialysis at Gezira Hospital for Renal Diseases and Surgery, Gezira State, Sudan. So, this study was conducted using ultrasound; to determine the Socio-demographic Characteristic factors and their relation to hemodialysis; in order to help physicians, patients and their families for planning to obtain better outcome of interventions. It was done during the period from February to April 2018. Renal disease is asymptomatic, so, if it is detected late their medical interventions will be ineffective.
The course of such disease can be changed or stopped by early therapeutic interventions [14]. Nephrologists, patients and their families are in great needs for information about End Stage Renal Diseases (ESRD) for planning and implementing preventive measures [15].

\section{Methods}

\subsection{Study Design}

It was an observational cross sectional facility base study.

\subsection{Study Area and Setting}

The study was conducted at Gezira Hospital for Renal Diseases \& Surgery, Gezira State, Sudan. It was established in $18 / 2 / 2002$. It serves the Central and Eastern States. The total population served by this hospital is about 7,000,000 . The hospital consists of six wards divided among two departments: Department of Urology and Surgery and Department of Nephrology. It has a capacity of 80 beds divided equally between urology and nephrology departments. It has integrated services that required management of their patients. The total number of machine for dialysis is 29 . The number of shifts per day is four. The total number of patients at $7 / 11 / 2017$ is 279 patients; pediatric male (2), adult male (180), and adult female (97).

\subsection{Study Populations and Sampling}

They were Sudanese Patients with ESRD on regular hemodialysis (HD) at the Gezira Hospital for Renal Diseases and Surgery. Fifty respondents were selected.

\subsection{Data Collection Methods and Techniques}

Structured questionnaire was used by direct interview.

\subsection{Data Management and Analysis}

Data was entered and analyzed using SPSS version 21. $P$ value $\leq 0.05$ was considered statistically significant.

\section{Results}

Thirty one $(62 \%)$ of the respondents was male and 19 $(38 \%)$ of them was female. The minimum age was 19 years while the maximum age was 70 years. The mean age was 45.10 years and the Std. Deviation was 14.755. Regarding residency, 1 (2\%) from East State, 1 (2\%) from West State; and $48(48 \%)$ from the Central State, i.e. the majority of them were from the Central State. About marital status 33 (66\%) were married while 17 (34\%) were not married. 


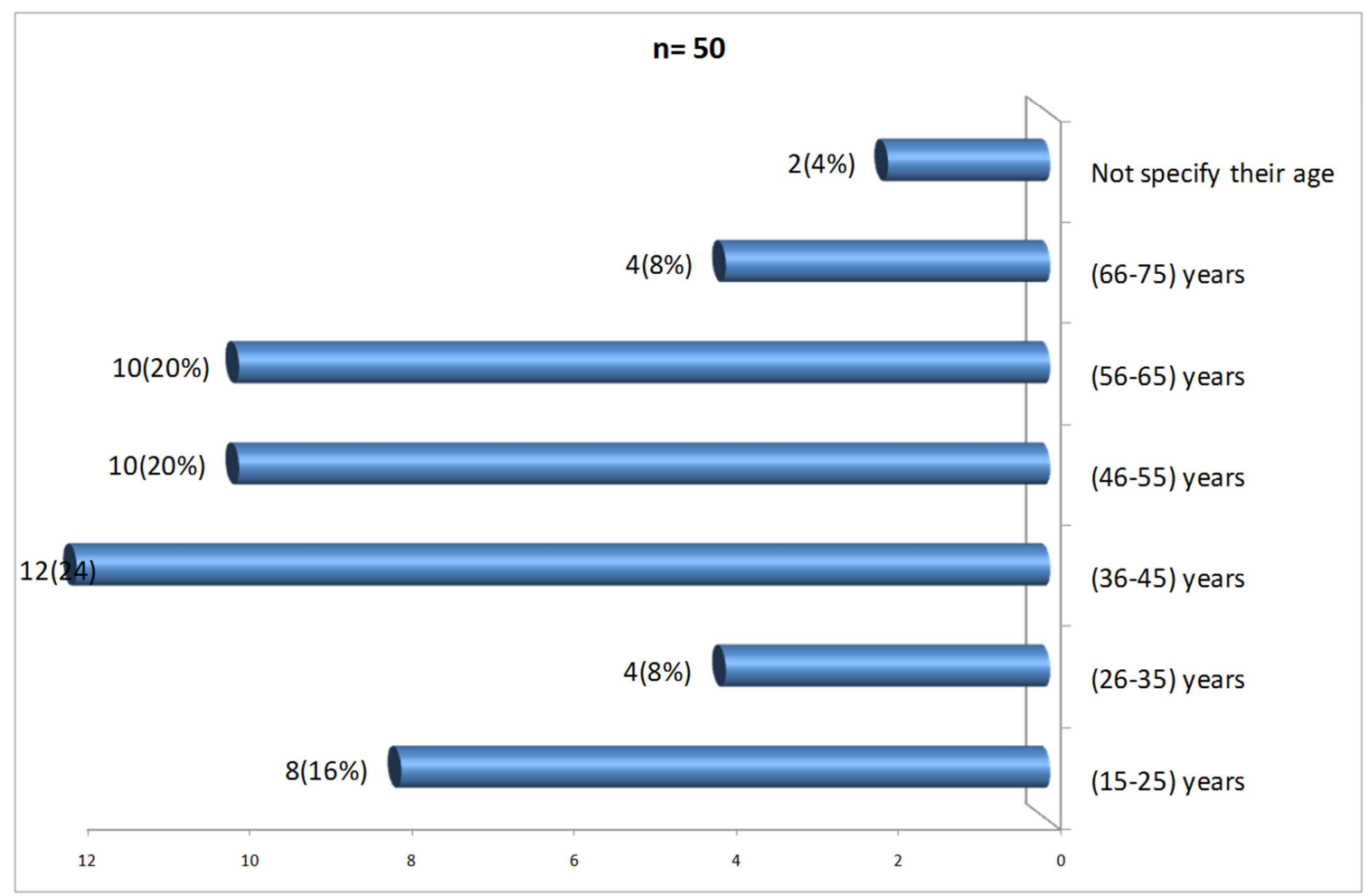

Figure 1. Age groups of patients on Hemodialysis at Gezira Hospital for Renal Diseases and Surgery, Gezira State, Sudan; 2018. $(n=50)$.

The distribution of the respondents among the different age group was as follows: (15-25) years 8 (16\%), (26-35) years 4 (8\%), (36-45) years $12(24 \%),(46-55)$ years $10(20),(56-65)$ years $10(20),(66-75)$ years $4(8 \%)$, and $2(4 \%)$ did not specify their age (Figure 1).

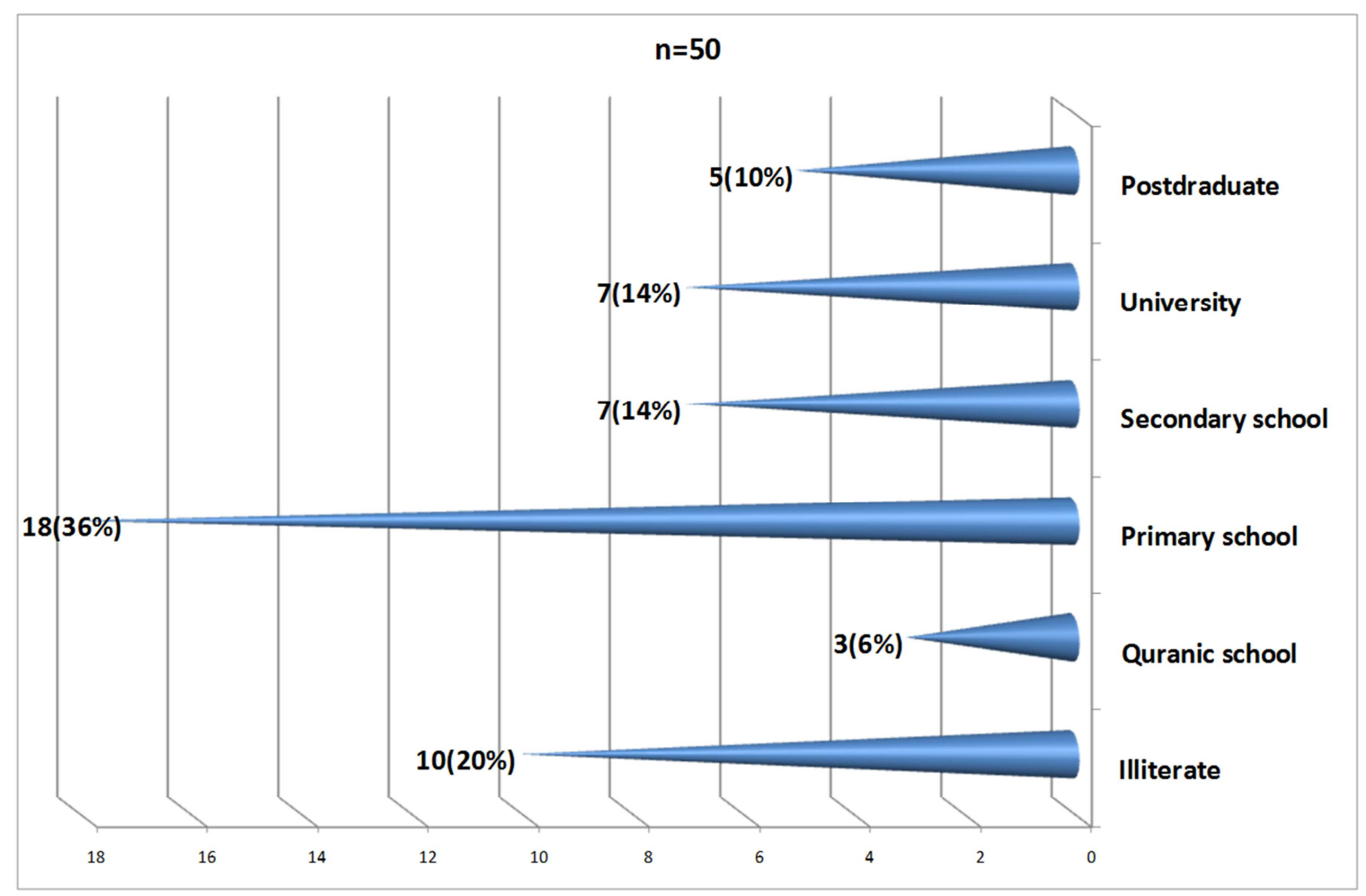

Figure 2. Educational level of patients on Hemodialysis at Gezira Hospital for Renal Diseases and Surgery, Gezira State, Sudan; 2018. $(n=50)$.

For education $10(20 \%)$ were illiterate, $3(6.0 \%)$ Khalwa, 18 (36\%) primary school, 7 (14\%) secondary school, 7 (14\%) university graduate, and $5(10 \%)$ had postgraduate certificate (Figure 2$)$. 


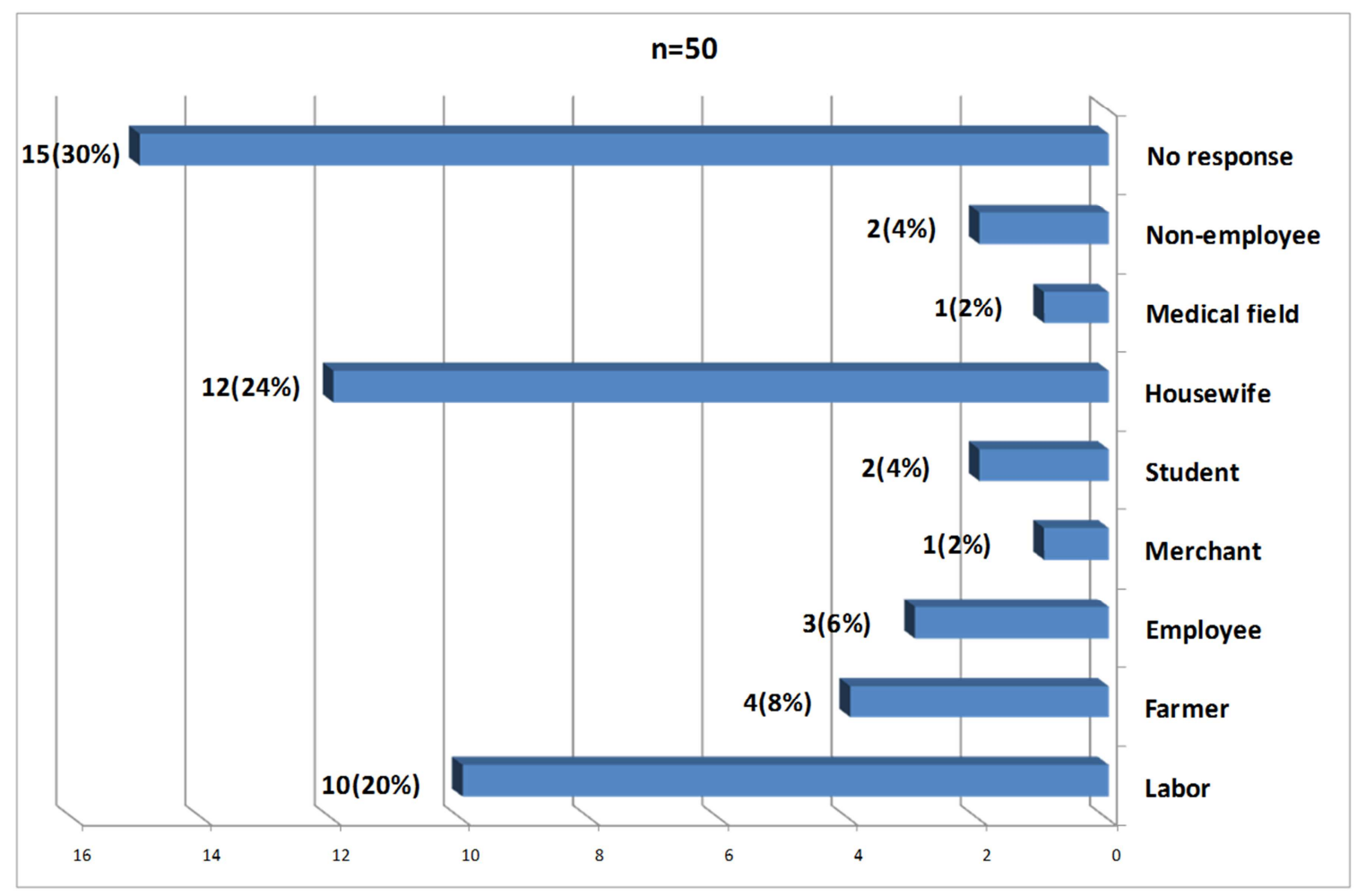

Figure 3. Occupation of patients on Hemodialysis at Gezira Hospital for Renal Diseases and Surgery, Gezira State, Sudan; 2018. $(n=50)$.

Their occupation was as follows: $10(20 \%)$ labor, $4(8 \%)$ were farmers, $3(6 \%)$ were employee, $1(2 \%)$ was a merchant, 2 (4\%) were students, 12 (24\%) were households, 1 (2\%) was from the medical field, 2 (4\%) were non-employee and $15(30 \%)$ did not response to identify their occupations (Figure 3 ).

Table 1. The relation between age group and marital status of patients on Hemodialysis at Gezira Hospital for Renal Diseases and Surgery, Gezira State, Sudan; $2018(n=50)$.

\begin{tabular}{|c|c|c|c|c|c|c|c|c|c|}
\hline \multirow{2}{*}{$\begin{array}{l}\text { Marital } \\
\text { status }\end{array}$} & \multicolumn{7}{|l|}{ Age group } & \multirow[b]{2}{*}{ Total } & \multirow[b]{2}{*}{ Pvalue } \\
\hline & (15-25) years & $(26-35)$ years & $(36-45)$ years & $(46-55)$ years & $(56-65)$ years & $(66-75)$ years & $\begin{array}{l}\text { Not specify } \\
\text { their age }\end{array}$ & & \\
\hline Married & 2 & 0 & 8 & 8 & 9 & 4 & 2 & 33 & \multirow{3}{*}{0.002} \\
\hline Not married & 6 & 4 & 4 & 2 & 1 & 0 & 0 & 17 & \\
\hline Total & 8 & 4 & 12 & 10 & 10 & 4 & 2 & 50 & \\
\hline
\end{tabular}

There is a strong statistical association between age group and marital status of the respondents $(P$ value $=0.002)($ Table 1).

\section{Discussion}

A cross sectional facility base study was done among Sudanese patients with ESRD on regular heamodialysis at Gezira Hospital for Renal Diseases and Surgery. Fifty respondents were selected. About $62 \%$ of the respondents were male. This was similar to what is reported in USA that male is more prone to heamodialysis than female [5]; and similar to what is reported in Ghana where the majority of patients $(64.5 \%)$ on heamodialysis are male [11]; in Cameron among patients on heamodialysis where $66 \%$ of respondents are male [12]; and in a study related to data from Asia-Africa that male is predominant $(66.7 \%)$ among patients with chronic kidney disease [13]. So, gender is an important factor related to ESRD.
The majority of study populations (96\%) were originally from the Central State of the Sudan. This may due to the location of the hospital.

The minimum age was 19 years while the maximum age was 70 years; with mean age of 45.10 years and Std. Deviation of 14.755. The maximum affected age group was the age group (36-45) years; followed by age groups (46-55) and (56-65) years. These findings were consistent to what is reported in Sudan [1, 10]; in Greece [8, 9]; in Cameron [12]; in a study related to data from Asia-Africa that the mean age is $49.27 \pm 16.7$ years among patients with chronic kidney disease [13]; and in USA that age (risk increase with age) is a risk factor for heamodialysis [5]. So, age is an important factor related to ESRD.

The married rate among respondents was $66 \%$. This is similar to what is reported internationally in Greece $[8,9]$; in Sudan [10]; and in a study related to data from Asia-Africa that the married rare is $70.6 \%$ among patients with chronic kidney disease [13]. So, the married rate is an important 
factor related to the outcome of ESRD.

Regarding level of education only $24 \%$ of respondents were graduated, which is a low level of education. This is similar to international findings reported in Greece $[8,9]$; in Sudan [10]; and in a study related to data from Asia-Africa that the undergraduate level of education is $40 \%$ among patients with chronic kidney disease [13]. So, the level of education is an important factor related to the outcome of ESRD.

About 58\% have no work and 20\% workers; so $78 \%$ of respondents were financially dependents on others. Also, this is similar to international findings as reported in Canada [6]; in Greece [9]; and in a study related to data from Asia-Africa that the employed rate is $34 \%$, low income group represents $41.6 \%$ and middle income group represents $37.3 \%$ among patients with chronic kidney disease [13]. So, the level of employment is an important factor related to ESRD.

\section{Conclusion}

Male is more prone to heamodialysis than female. Risk for heamodialysis increases with increased age. The married rate is an important factor related to the outcome of ESRD. Low levels of education together with low income level of employment are important factors related to ESRD.

\section{Recommendations}

Consideration of social aspects of the general population and improvement of their life is highly recommended to compact diseases. Another research among patients on heamodialysis may help to give a clear picture about the situation.

\section{References}

[1] Banaga ASI, et al. 2015, Causes of end stage renal failure among haemodialysis patients in Khartoum State/Sudan. BMC Res Notes, 8: 502. doi: 10.1186/s13104-015-1509-x. PMCID: PMC4589074.

[2] Elsharif ME \& Elsharif EG 2011, Causes of End-Stage Renal Disease in Sudan: A Single-Center. Saudi J Kidney Dis Transpl; 22 (2): 373-376.

[3] Snell, R. S., (2012). Clinical Anatomy by Regions $\left(9^{\text {th }}\right.$ Edition). Wolters Kluwer / Lippincott Williams and Wilkins, Hong Kong, pp (206-215).
[4] Goldman L, et al., 2016, Chronic kidney disease, In: Goldman-Cecil Medicine. 25th ed. Philadelphia, Pa.: Saunders Elsevier. http://www.clinicalkey.com

[5] EBSCO 2016, Chronic kidney disease (CKD) in adults, viewed 4 October 2016, http://www.dynamed.com/topics/dmp AN T115336/

[6] Chartier et al. Prevalence, socio-demographic characteristics, and comorbid health conditions in pre-dialysis chronic kidney disease: results from the Manitoba chronic kidney disease cohort. BMC Nephrology (2018) 19: 255 https://doi.org/10.1186/s12882-018-1058-3.

[7] Hamody A. T., Kareem A. K., Al-Yasri A. S., Sh. Ali A. A. Depression in Iraqi Hemodialysis Patients. Arab Journal of Nephrology and Transplantation. 2013 Sep; 6 (3): 169-72.

[8] Theofilou P. A. The Impact of Sociodemographic and Psychological Variables on Quality of Life in Patients With Renal Disease: Findings of a Cross-Sectional Study in Greece. World J Nephrol Urol • 2012; 1 (4-5): 101-106.

[9] Theofilou P. Depression and Anxiety in Patients with Chronic Renal Failure: The Effect of Sociodemographic Characteristics. International Journal of Nephrology, Volume 2011, Article ID 514070, 6 pages. doi: 10.4061/2011/514070.

[10] Awadalla A. W.; Ohaeri J. U.; Al-Awadi S. A.; and Tawfiq A. M. Diabetes Mellitus Patients' Family Caregivers' Subjective Quality of Life. JOURNAL OF THE NATIONAL MEDICAL ASSOCIATION VOL. 98, NO. 5, MAY 2006727.

[11] Amoako Y. A., Laryea D. O., Bedu-Addo G., Andoh H., Awuku Y. A. Clinical and demographic characteristics of chronic kidney disease patients in a tertiary facility in Ghana. Pan African Medical Journal. 2014; 18: 274 doi: 10.11604/pamj.2014.18.274.4192. This article is available online at: http://www.panafrican-medjournal.com/content/article/18/274/full/.

[12] Halle M. P., Takongue C., Kengne A. P., Kaze F. F. and Ngu K. B. Epidemiological profile of patients with end stage renal disease in a referral hospital in Cameroon. Halle et al. BMC Nephrology (2015) 16: 59. DOI 10.1186/s12882-015-0044-2.

[13] Bapat U., Nayak S. G., Kedleya P. G., Gokulnath. Demographics and Social Factors Associated with Acceptance of Treatment in Patients with Chronic Kidney Disease. Saudi J Kidney Dis Transpl 2008; 19 (1): 132-136.

[14] USRDS 2015, ESRD in the United States, Annual Data Report Volume 2.

[15] Elamin AEM, Mohammed NAA \& Modawe G 2012, Aetiology of End-Stage Renal Disease among adult Sudanese patient, Sudan JMS, Volume 7, Number 4, 255-258. 